\title{
Nanoparticle analysis for various medicinal drugs and human body saliva at macromolecular level
}

\author{
G. S. Uthayakumar · Senthilkumar • \\ S. Inbasekaran · A. Sivasubramanian · \\ S. Justin Packia Jacob
}

Received: 12 June 2014/ Accepted: 18 August 2014/Published online: 28 August 2014

(C) The Author(s) 2014. This article is published with open access at Springerlink.com

\begin{abstract}
The spectral bio-diagnosis of normal human body saliva sample shows the following functional compounds and it is related to various proteins and enzymes. Because of the presence of water in the saliva sample, the hydroxyl group is observed in the form of $\mathrm{O}-\mathrm{H}$ at $3,305 \mathrm{~cm}^{-1}$, because of the presence of lipids, the functional group $\mathrm{C}-\mathrm{H}$ is obtained from 2,928 to $2,856 \mathrm{~cm}^{-1}$, due to the presence of amide- $\mathrm{I}$ in the form of $\mathrm{C}=\mathrm{N}$ and $\mathrm{C}=\mathrm{C}$ obtained at $1,658 \mathrm{~cm}^{-1}$, the proteins are exhibited. Due to the presence of aliphatic $\mathrm{CH}_{2}$, the Lipids, Adenine, Cytosine, Collagen are observed at $1,455 \mathrm{~cm}^{-1}$, because of the presence of Carbohydrates, Phospholipids, Nucleic acids, the functional groups $\mathrm{C}=\mathrm{O}$ and $\mathrm{P}=\mathrm{O}$ from 1,159 to $1,064 \mathrm{~cm}^{-1}$ are exhibited. Due to the presence of Phenylalanine, Tyrosine, Cystine and Hydroxyapatite $\mathrm{C}-\mathrm{C}$ twist, $\mathrm{C}-\mathrm{C}$ stretch, $\mathrm{C}-\mathrm{S}$ stretch and $\mathrm{PO}_{4}{ }^{2-}$ are observed at 748 and $483 \mathrm{~cm}^{-1}$. Silver nanoparticle has attracted considerable interest due to their extensive applicability in various areas such as electronics, catalysis, chemistry, energy and medicine. To study the opto-electronics properties of the samples, it was mixed with silver nanoparticles and characterized.
\end{abstract}

G. S. Uthayakumar $(\bowtie) \cdot$ S. Justin Packia Jacob

St.Joseph's College of Engineering, Chennai 600119, India

e-mail: guthayakumar@gmail.com

Senthilkumar

Agni College of Engineering, Chennai 603103, India

S. Inbasekaran

CLRI, Adyar 600020, India

A. Sivasubramanian

Tagore Institute of Engineering and Technology, Salem,

Tamilnadu, India
Keywords Nano-optics - Raman spectroscopy - SEM • Saliva . Human body

\section{Introduction}

In this research paper, the biomedical optical analytical techniques such as ultraviolet(UV) spectroscopy, Fourier transform infrared (FTIR) spectroscopy and Fourier transform-Raman spectroscopy are used to characterize and quantize the medicinal drugs. All the medicinal drugs are characterized using FTIR and FT-Raman analytical techniques before feeding to the patient. The saliva sample is collected after $5 \mathrm{~h}$ duration from each patient and investigated for the presence and absence of bacteria in the human saliva. This is very useful for the analysis of all the diseases in the body. The first drug sample(orange sample) given for gastric problem by an expert in traditional medical field is analyzed for various chemical compositions. After taking this particular drug sample, the saliva sample was collected from the same patient after $7 \mathrm{~h}$ duration and investigated the chemical compositions. The reaction with human body tissues shows that it contains very few functional groups in comparison with original saliva sample. Hence, it is confirmed that the disease was also cured after a few days (around 10 days); i.e., unwanted bacteria are destroyed and required bacteria are always available in the form of proteins and lipids.

In recent times, nanomaterials have gained significant attention throughout the world today and there is an increasingly frenetic search for new nanomaterials and methods to make them. Silver nanoparticles, as a significant member of the noble metal nanoparticles, are excellent substrates for surface enhanced raman scattering (SERS) to probe single molecules, and are excellent as catalysts for 
accelerating some chemical reactions. A number of approaches are available for the synthesis of silver NPs. For example, silver nanoparticles are synthesized by chemical, electrochemical (Yin et al. 2003), radiation, and photochemical techniques (Callegari et al. 2003) as well as Langmuir-Blodgett (Zhang et al. 2006; Stone et al. 2004) and biological techniques (Naik et al. 2002). In the chemical synthesis methods, the reactants and starting materials used in these reactions are toxic and potentially hazardous. In contrast, synthetic methods based on naturally occurring biomaterials provide an alternative, environmental-friendly means of obtaining these nanoparticles.

Exploration of the plant systems as the potential nanofactories, has heightened interest in the biological synthesis of nanoparticles. In the earlier work Justin et al. (2012) reported the biosynthesis of nanoparticles using plant leaf extracts and their potential application. They studied bioreduction silver ions by extracts of Piper longum (Justin Packia Jacob 2012) and neem leaf (Stone et al. 2004). Keeping this in mind in the present study, silver nanoparticles were prepared using dried fruit extracts and characterized.

One of the most important medical diagnostic significances is the presence in saliva of the bacteria Helicobacter pylori (which normally absent), signifying possible peptic ulcers, possible gastritis or stomach cancer (Mark et al. 2004; Stone et al. 2004). One of the most important noninvasive diagnostic uses of saliva is the estimation of blood (plasma) glucose concentration (BG). As these spectral changes are very specific and unique, they are also called fingerprint. The advantages of the methods include that they are non-destructive and do not require extrinsic contrast-enhancing agents (Uceda Otero et al. 2013). The broad range of vibrational spectroscopic applications which focus on imaging and fiber-optical techniques is discussed to study mineralized tissue (bone, teeth), skin, brain, the gastrointestinal tract (mouth, pharynx, esophagus, colon), breast, arteries, cartilage, cervix uteri, the urinary tract (prostate, bladder), lung, ocular tissue, liver, heart, and spleen. Experimental techniques are summarized demonstrating the possibilities and prospects of these methods in various health care fields of bio-diagnostics to detect and characterize diseases, tumors, and other pathologies. When sending a light through biological tissue, the emerging light gives some information about the structures and the absorption and scattering characterization of the intervening tissues.

\section{Materials and methods}

Fourier Transform Infrared Spectrometer, scan range: MIR $4,000-400 \mathrm{~cm}^{-1}$, resolution $1.0 \mathrm{~cm}^{-1}$ sample quantity used $50 \mathrm{mg}$, solid. The Perkin Elmer Spectrum-1 FTIR instrument consists of globar and mercury vapor lamp as sources, an interferometer chamber comprising of $\mathrm{KBr}$ and mylar beam splitters followed by a sample chamber and detector. Entire region of $4,000-450 \mathrm{~cm}^{-1}$ is covered by this instrument. FT-Raman spectrometer is a multiRAM, stand alone model. The spectral range is $4,000-50 \mathrm{~cm}^{-1}$. The laser source is $\mathrm{Nd}$ YAG 1,064 $\mathrm{nm}$. The spectrometer has a large sample compartment to accommodate different sample formats, from powders to liquids in vials. We used BRUKER RFS 27 stand alone Fourier Transform-Raman spectrometer, scan range: $4,000-50 \mathrm{~cm}^{-1}$, resolution $2 \mathrm{~cm}^{-1}$ and sample quantity used $50 \mathrm{mg}$, both solid and liquid samples are used.

Drugs are given to different patients for gastric problem such as Orange (Powder sample), Blue (Tablet), Brown (Ayurvedic Tablet), Green (Liquid sample) and it is experimented with FTIR and FT-Raman for comparative characterization of all the samples and also it is investigated at nano scale level using Scanning Electron Microscopy (SEM). SEM plays an important role in the quantitative analysis for characterization of size, shape and distribution of nanoscale and sub-micron particulate systems. This technique can serve as an absolute reference standard to support the development of particle size distribution techniques. The wide variety of signals generated in the SEM imaging process permits the selection of an imaging mode that best fits the analytical task.

\section{Synthesis of silver nanoparticles}

$1 \mathrm{mM}$ aqueous solution of silver nitrate (AgNO3) was prepared and used for the synthesis of silver nanoparticles. $3 \mathrm{ml}$ of Ficus Carica fruit extract was added into $40 \mathrm{ml}$ of aqueous solution of $1 \mathrm{mM}$ silver nitrate for reduction into $\mathrm{Ag}+$ ions and incubated overnight at room temperature in dark. The fruit extract silver nitrate solution was exposed to sunlight till the appearance of dark brownish color.

\section{Characterization of silver nanoparticles}

The reduction of pure $\mathrm{Ag}+$ ions was monitored by observing a brownish colouration at the synthesis phase. The concentration of AgNP produced was measured using a Systronics UV double-beam spectrophotometer (model 2201), at a resolution of $1 \mathrm{~nm}$, between 200 and $600 \mathrm{~nm}$ using 10-mm optical path length quartz cuvettes. FTIR (Fourier transform IR) studies on the samples were carried out using Perkin Elmer Spectrum 1 FTIR spectroscopy at SAIF, IIT Madras, scanned at range $450-4,000 \mathrm{~cm}^{-1}$ of resolution to ensure the formation of silver nanoparticles. A scanning electron microscope (OXFORD 200 FEG, FESEM) was used to record the micrograph images of synthesized AgNPs. 


\section{Results and discussions}

The UV-Vis spectroscopy analysis was done to confirm the presence of silver nanoparticles. The appearance of dark brownish color was due to excitations of surface plasmon vibrations. The analysis was done by scanning the samples between the range of $300-700 \mathrm{~nm}$ which gave the $\lambda \max$ value at $425 \mathrm{~nm}$.

FTIR absorption spectra of silver nanoparticles produced by extract are shown in Fig. 1, absorbance band are observed in the region of 4,000-50 $\mathrm{cm}^{-1}$. The absorbance bands at 3,394 and 2,925 $\mathrm{cm}^{-1}$ are broadened in the extract alone, but the narrow band in the silver nanoparticles showed that reduction of silver ions in the nanoparticles. The band at $1,625 \mathrm{~cm}^{-1}$ showed that the $\mathrm{N}-\mathrm{H}$ bounding vibrate due to the presence of amides and that is indicated involvement of amides from the plant extract in the reduction of silver nanoparticles. The shift of the band in fruit extract at 1,422-1,384 $\mathrm{cm}^{-1}$ after the bioreduction of AgNPs indicated the $\mathrm{C}=\mathrm{C}$ stretching mode in the aromatic compounds which confirmed the aromatic compounds like flavanoids in the fruit extract are responsible for the reduction of AgNPs.

The sizes of the spherical Ag nanoparticles were found to be in the range of $66.7-89.4 \mathrm{~nm}$ (Fig. 2). The IR spectrum of a compound is essentially the superposition of absorption bands of specific functional groups. For qualitative analysis, one of the best features of an IR spectrum is that the absorption or the lack of absorption in the specific frequency regions can be correlated with specific stretching and bending motions of the molecule. Thus, by interpretation of the spectrum, it is possible to state that certain functional groups are present in the material and that certain others are absent. After the presence of a particular fundamental stretching frequency has been established, closer observation of the shape and exact position of an absorption band often yields additional information.

The shape of an absorption band around $3,000 \mathrm{~cm}^{-1}(3.3 \mu \mathrm{m})$ gives the presence of $\mathrm{C}-\mathrm{H}$ group. Alkyl groups have their $\mathrm{C}-\mathrm{H}$ stretching vibration at the wavenumber $3,000 \mathrm{~cm}^{-1}$, whereas alkenes and aromatics have slightly higher wavenumbers than alkyl gruops. The $\mathrm{CH}_{3}$ group gives rise to an asymmetric stretching mode (Fig. 1) at $2,960 \mathrm{~cm}^{-1}(3.38 \mu \mathrm{m})$ and a symmetric mode at $2,870 \mathrm{~cm}^{-1}(3.48 \mu \mathrm{m})$. For- $\mathrm{CH}_{2}-$ these bands occur at $2,930 \mathrm{~cm}^{-1}(3.42 \mu \mathrm{m})$ and $2,850 \mathrm{~cm}^{-1}(3.51 \mu \mathrm{m})$ (Raziya Sultana et al. 2012). For ethers, the one important band appears near $1,100 \mathrm{~cm}^{-1}(9.09 \mu \mathrm{m})$ and is due to the antisymmetric stretching mode of the $-\mathrm{C}-\mathrm{O}-\mathrm{C}-$ links. For alcohols, the most useful absorption is that due to the stretching of the $\mathrm{O}-\mathrm{H}$ bond. In the free or unassociated state, it appears as a weak but sharp at about $3,600 \mathrm{~cm}^{-1}$ $(2.78 \mu \mathrm{m})$. Hydrogen bonding will greatly increase the intensity of the band and move it to lower frequencies and, if the hydrogen bonding is concentration dependent, whereas intra-molecular hydrogen bonding is not concentration dependent. Measurements in solution under different concentrations are invaluable. The spectrum of an acid is quite distinctive in shape and breadth (Fig. 3) in the high-

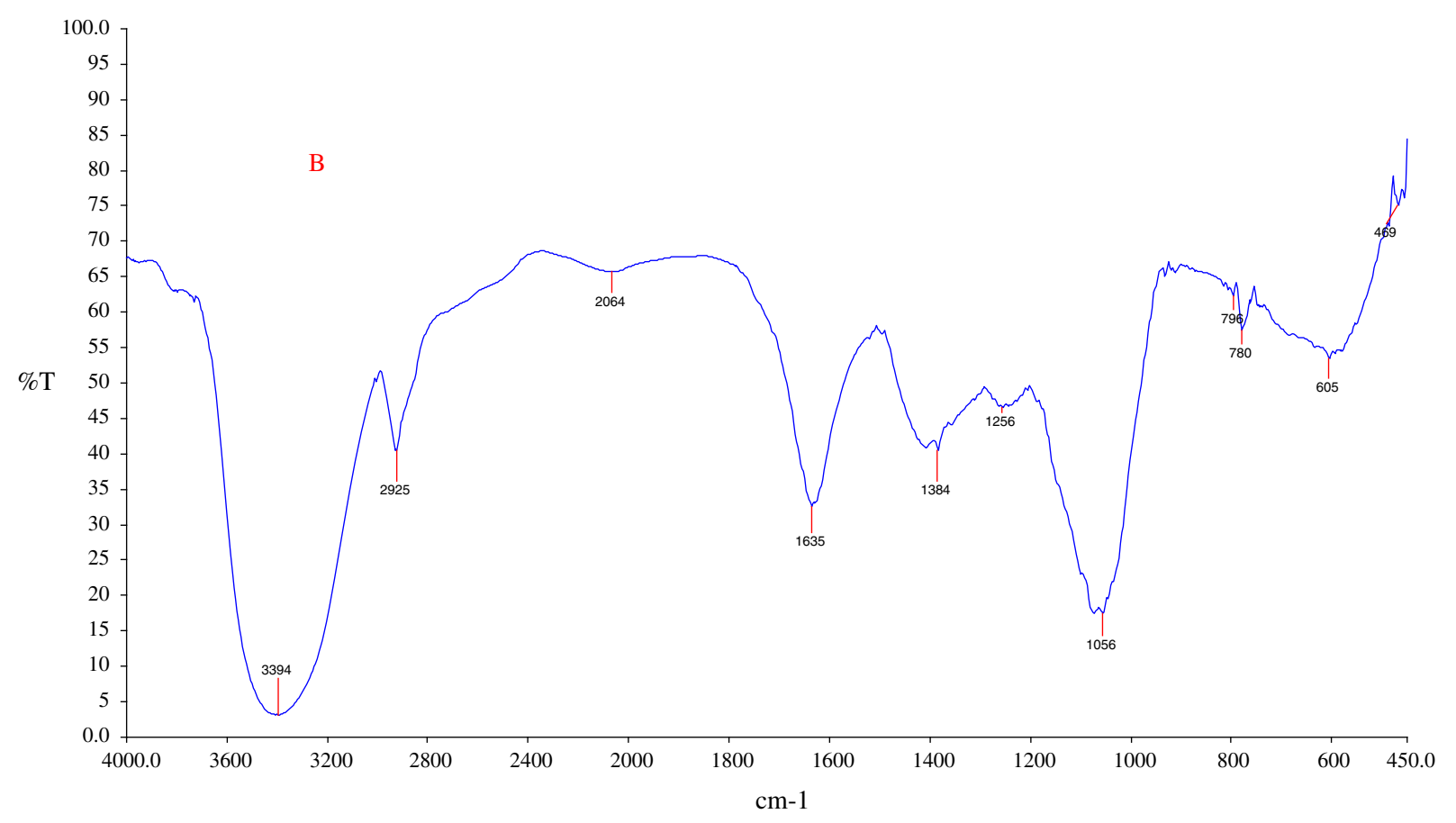

Fig. 1 FTIR spectra of silver nanoparticles 
Fig. 2 SEM image of silver nanoparticles

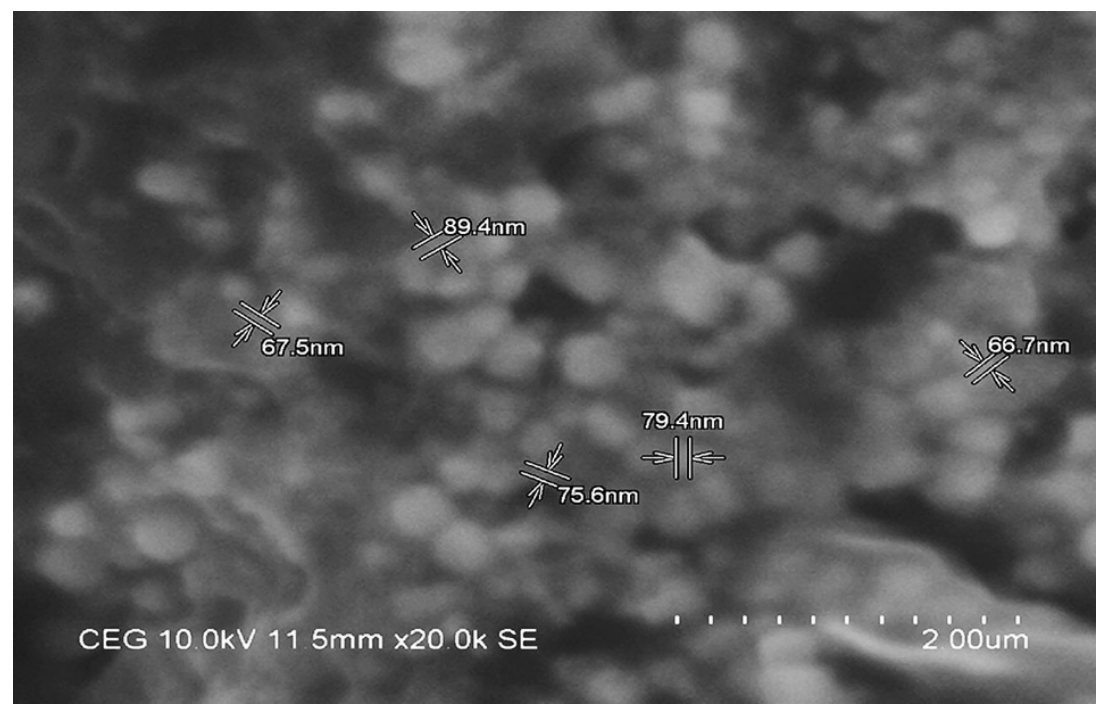

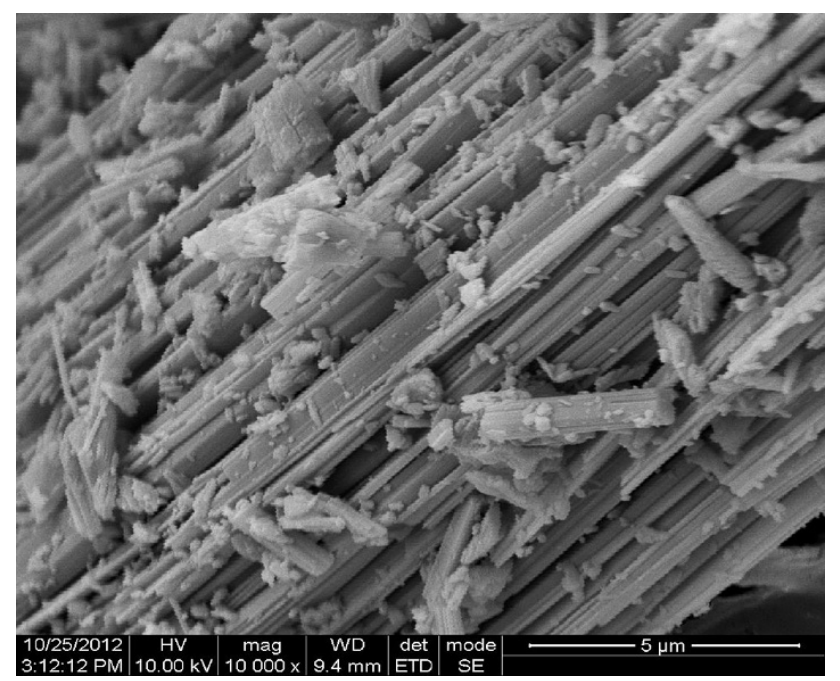

Fig. 3 SEM image of Orange color sample

frequency region. The distinction between the several types of alcohols is often possible on the basis of the $\mathrm{C}-\mathrm{O}$ stretching absorption bands, as indicated in Table 1.

From FTIR spectra of brown sample (Uthayakumar and Sivasubramanian 2013), the number of data points between two peaks $3,404-3,416$ is 13 and the mean peak value is $3,410 \mathrm{~cm}^{-1}$, it belongs to $-\mathrm{NH}_{2}$ in aromatic amines, primary amines and amides [N-H stretch, intensity: mediumstrong (Raziya Sultana et al. 2012)]. The standard deviation is 3.89 . The mean transmittance value is $3.18 \%$ and its standard deviation is 0.0083 . The maximum transmittance value is $3.19 \%$ and the minimum value is $3.17 \%$. Since the significance value is 0.15502 , it can be inferred that there is a significant relationship between the two variables. Also, the correlation coefficient value of 0.41 shows that there is $41 \%$ positive correlation between the two variables. The next peak value lies between 2,985 and
$3,404 \mathrm{~cm}^{-1}$ and thus the mean peak value is $3,194.5 \mathrm{~cm}^{-1}$ and the standard deviation is 121.38 because the number of data points between peak values is 420 . The respective transmittance value is $8.97 \%$ and the standard deviation is 5.95. The minimum absorbance value is $3.17 \%$ and the maximum absorbance value is $22.43 \%$. Since the significance value is 0.00 , it can be inferred that there is a significant relationship between the two variables. Also, the correlation coefficient value of -0.93 shows that there is $93 \%$ negative correlation between the two variables.

The substitution pattern of an aromatic ring can be deduced from a series of weak but very useful bands in the region $2,000-1,670 \mathrm{~cm}^{-1}(5-6 \mu \mathrm{m})$ coupled with the position of the strong bands between 900 and $650 \mathrm{~cm}^{-1}$ (11.1 and $15.4 \mu \mathrm{m})$ which are due to the out-of-plane bending vibrations. Absence of the symmetrical breathing mode at $690-710 \mathrm{~cm}^{-1}$ in the spectra of para and orthosubstituted rings is helpful. Ring stretching modes are observed near 1,600, 1,570 and $1,500 \mathrm{~cm}^{-1}(6.25,6.37$ and $6.67 \mu \mathrm{m})$. These characteristic absorption patterns are also observed with substituted pyridines and polycyclic benzenoid aromatics. When analyzing formulated products like orange sample, there is often a need to evaluate and control wide variety of material characteristics many of which require accurate, unobscured observations of surface form and structure. The wide variety of signals generated in the SEM imaging process permits the selection of an imaging mode that best fits the analytical objective. From for the liquid yellow sample (Uthayakumar and Sivasubramanian 2013), the following negative correlation coefficient mean peaks are obtained 656, 941.5, 1,033, 1,108.5, 1,141, 1,440, $1,700.5,2,193,2,514,2,767.5,2,889 \mathrm{~cm}^{-1}$.

From Fig. 4, the first mean peak was observed at $476 \mathrm{~cm}^{-1}$, the maximum peak value is $493 \mathrm{~cm}^{-1}$ and the minimum peak value is $459 \mathrm{~cm}^{-1}$. The respective standard 
Table 1 Dominant peak obtained from absorption spectra for various samples

\begin{tabular}{|c|c|c|c|c|c|c|c|c|c|c|}
\hline \multirow[t]{2}{*}{ Functional groups } & \multicolumn{2}{|c|}{ Orange sample } & \multicolumn{2}{|c|}{ Blue sample } & \multicolumn{2}{|c|}{ Yellow sample } & \multicolumn{2}{|c|}{ Green sample } & \multicolumn{2}{|c|}{ Brown sample } \\
\hline & WN & VI & WN & VI & WN & VI & WN & VI & $\mathrm{WN}$ & VI \\
\hline \multicolumn{11}{|l|}{ Carboxylic acid } \\
\hline $\mathrm{O}-\mathrm{H}$ stretching & - & - & 2,924 & $\mathrm{~S}$ & 2,924 & $\mathrm{~S}$ & - & - & 2,918 & $\mathrm{~S}$ \\
\hline $\mathrm{C}-\mathrm{O}$ stretching & - & - & 1,212 & S & 1,235 & $\mathrm{~S}$ & - & - & 1,207 & $\mathrm{~S}$ \\
\hline $\mathrm{O}-\mathrm{H}$ bending & - & - & 1,451 & VS & 1,418 & VS & 1,458 & $\mathrm{~S}$ & 1,451 & $\mathrm{~S}$ \\
\hline \multicolumn{11}{|l|}{ Amine } \\
\hline $\mathrm{N}-\mathrm{H}$ stretching & 3,434 & VS & 3,403 & VS & 3,472 & M & 3,391 & $\mathrm{~S}$ & 3,404 & $\mathrm{~S}$ \\
\hline $\mathrm{N}-\mathrm{H}$ bending & 1,642 & $\mathrm{~S}$ & 1,617 & $\mathrm{~S}$ & 1,655 & $\mathrm{~S}$ & 1,654 & $\mathrm{~S}$ & 1,616 & $\mathrm{~S}$ \\
\hline $\mathrm{C}-\mathrm{N}$ stretching & 1,336 & $\mathrm{~S}$ & 1,339 & $\mathrm{~S}$ & - & - & - & - & - & - \\
\hline \multicolumn{11}{|l|}{ Amide } \\
\hline $\mathrm{N}-\mathrm{H}$ stretching & 3,434 & VS & 3,403 & VS & 3,472 & M & 3,391 & $\mathrm{~S}$ & 3,404 & $\mathrm{~S}$ \\
\hline $\mathrm{C}-\mathrm{O}$ stretching & 1,642 & $\mathrm{~S}$ & 1,617 & $\mathrm{~S}$ & 1,655 & $\mathrm{~S}$ & 1,654 & $\mathrm{~S}$ & 1,616 & $\mathrm{~S}$ \\
\hline \multicolumn{11}{|l|}{ Amino Acids } \\
\hline $\mathrm{N}-\mathrm{H}$ stretching & - & - & 2,924 & $\mathrm{~S}$ & 2,924 & S & - & - & 2,918 & $\mathrm{~S}$ \\
\hline $\mathrm{C}-\mathrm{O}$ stretching & - & - & 1,451 & $\mathrm{~S}$ & 1,418 & VS & 1,458 & $\mathrm{~S}$ & 1,451 & $\mathrm{~S}$ \\
\hline $\mathrm{N}-\mathrm{H}$ bending & - & - & 1,451 & $\mathrm{~S}$ & 1,418 & VS & 1,458 & $\mathrm{~S}$ & 1,451 & $\mathrm{~S}$ \\
\hline \multicolumn{11}{|l|}{ Sulfonyl } \\
\hline \multirow[t]{2}{*}{$\mathrm{S}=\mathrm{O}$ stretching } & 1,396 & VS & 1,339 & $\mathrm{~S}$ & 1,377 & $\mathrm{~S}$ & - & - & - & - \\
\hline & 1,336 & $\mathrm{~S}$ & 1,339 & $\mathrm{~S}$ & 1,377 & $\mathrm{~S}$ & - & - & - & - \\
\hline \multicolumn{11}{|l|}{ Sulfonate } \\
\hline $\mathrm{S}=\mathrm{O}$ stretching & 1,396 & VS & 1,339 & $\mathrm{~S}$ & 1,377 & $\mathrm{~S}$ & - & - & - & - \\
\hline $\mathrm{S}-\mathrm{O}$ stretching & 901 & M & - & - & 968 & $\mathrm{~S}$ & - & - & 893 & M \\
\hline \multicolumn{11}{|l|}{ Polysaccharide } \\
\hline \multicolumn{11}{|l|}{$\mathrm{C}-\mathrm{O}-\mathrm{C}$} \\
\hline \multicolumn{11}{|l|}{ Nitrate } \\
\hline $\mathrm{Si}-\mathrm{H}$ stretching & 901 & M & - & - & - & - & 861 & VS & 872 & VS \\
\hline $\mathrm{N}-\mathrm{H}$ bending & - & - & 814 & VW & - & - & 802 & VW & 814 & W \\
\hline \multicolumn{11}{|l|}{ Chlorate } \\
\hline C-H stretching & 856 & W & - & - & - & - & 861 & W & 854 & W \\
\hline \multicolumn{11}{|l|}{ Carbohydrate } \\
\hline $\mathrm{N}-\mathrm{H}$ wagging & 775 & W & 762 & W & 722 & W & 752 & W & 764 & W \\
\hline
\end{tabular}

deviation was obtained as 10.25 . The transmittance value is $91.84 \%$, the minimum absorbance value is $87.27 \%$ and the maximum absorbance value is $94.6 \%$. The respective standard deviation is 2.3 because the numbers of data points between these two peak values are 35 . The respective correlation coefficient is -0.96311 . This peak frequency belongs to $\mathrm{NO}_{2}$ in nitro compounds $\left(\mathrm{NO}_{2}\right.$ rocking, intensity $\mathrm{m}-\mathrm{s}$ ). Since the significance value is 0.04 , it can be inferred that there is a significant relationship between the two variables. Also, from the correlation coefficient value of -96.31 shows that there is $96 \%$ negative correlation between the two variables. The particle size of the blue color sample ranges from 183.7 to $207.4 \mathrm{~nm}$ (Fig. 4). At the surface level analysis using scanning electron microscopy, the following particles are identified at different frequencies, 188.3, 203.5, $197.8 \mathrm{~nm}$.

\section{Conclusion}

SEM combined with Image analysis is always a promising analytical technique for generating particle distribution profiles as well as surface characteristics with the possibility to visually reevaluate the data by reassessing the particle size. The technique holds promise for characterization of the size and shape of unknown products with relatively wide distribution profiles from the nanometer to the micron range. Saliva has multiple potential advantages over blood testing, as recently reviewed. These include the fact that saliva collection is considered non-invasive by patients; collection of saliva is safer (needle stick risk eliminated); it is convenient to collect (phlebotomists are not required); and it can be collected at home and delivered to nearby facilities. For specific purposes, it may even be 


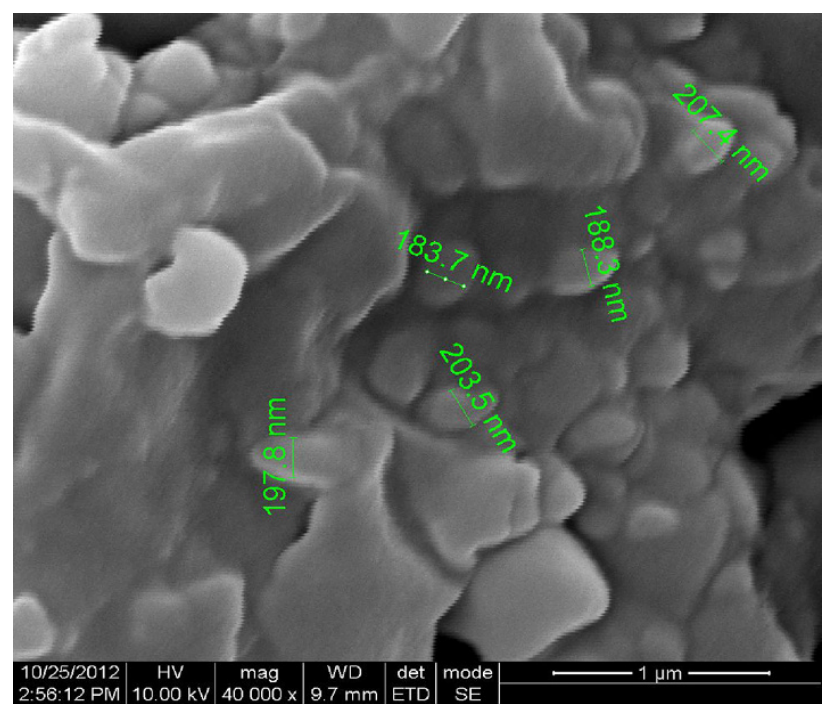

Fig. 4 SEM image of Blue color sample

possible to mail saliva samples from a patient's home to the point of analysis. In the long term, it has been conceived that an increased interest in salivary diagnostics will "help catalyze a shift (in medical practice) from disease diagnosis to health surveillance". It remains to be seen whether the non-invasive salivary (blood glucose-BG) estimation can prove as reliable as the finger-prick/blood drop/colorimeter test now most widely used by diabetics.

For qualitative analysis, SEM plays an important role in the quantitative analysis of characterization of size, shape, diameter and distribution of nanoscale and sub-micron particulate systems. In various literatures, the particle size distribution analysis of nanoscale and sub-micron polystyrene latex spheres has been described. Since, these products are characterized by a narrow distribution, only a limited number of particles need to be analyzed which allowed the use of elaborate manual procedures in the SEM analysis of these products. However, once the size (diameter) distribution of the product gets broader and more particles need to be counted, the automation offered by the use of SEM technology. The carbonyl group is not difficult to recognize, it is often the strongest band in the spectrum. Its exact position in the region, extending from about 1,825 to $1,575 \mathrm{~cm}^{-1}(5.48-6.35 \mu \mathrm{m})$, is dependent upon the double-bond character of the carbonyl group. Anhydrides usually show a double absorption band. Aldehydes are distinguished from ketones by the additional $\mathrm{C}-\mathrm{H}$ stretching frequency of the $\mathrm{CHO}$ group at about $2,720 \mathrm{~cm}^{-1}$ $(3.68 \mu \mathrm{m})$. In esters, two bands related to $\mathrm{C}-\mathrm{O}$ stretching and bending are recognizable between 1,300 and
$1,040 \mathrm{~cm}^{-1}(7.7$ and $9.6 \mu \mathrm{m})$ in addition to the carbonyl band. The carboxyl group, in a sense, shows bands arising from the superposition of $\mathrm{C}=\mathrm{O}, \mathrm{C}-\mathrm{O}, \mathrm{C}-\mathrm{OH}$, and $\mathrm{O}-\mathrm{H}$ vibrations (Uthayakumar and Sivasubramanian 2014). Of 5 characteristics bands, three of these $(2,700,1,300$ and $943 \mathrm{~cm}^{-1}$ ) are associated with vibrations of the carboxyl $\mathrm{OH}$. They disappear when the carboxylate ion is formed. When the acid exists in the dimeric form, the $\mathrm{O}-\mathrm{H}$ stretching band at $2,700 \mathrm{~cm}^{-1}$ disappears, but the absorption band at $943 \mathrm{~cm}^{-1}$ due to $\mathrm{OH}$ out-of-plane bending of the dimer remains.

Open Access This article is distributed under the terms of the Creative Commons Attribution License which permits any use, distribution, and reproduction in any medium, provided the original author(s) and the source are credited.

\section{References}

Callegari A, Tonti D, Chergui M (2003) Photochemically grown silver nanoparticles with wavelength-controlled size and shape. Nano Lett 3(11):1565

Justin Packia Jacob S, Finub S, Anand Narayanan (2012) Synthesis of silver nanoparticles using Piper longum leaf extracts and its cytotoxic activity against Hep-2 cell line. Colloid Surf B Biointerface 91:212-214

Mark Sahu RK, Kantarovich K, Podshyvalov A, Guterman H, Goldstein J, Jagannathan R, Argov S, Mordechai S (2004) Distinction of cervical cancer biopsies by use of infrared microspectroscopy and probabilistic neural networks. J Biomed Opt 9:558-567

Naik RR, Stringer SJ, Agarwal G, Jones S, Stone MO (2002) Biomimetic synthesis and patterning of silver nanoparticles. Nature Mater 1:169-172

Raziya Sultana R, Zafarullah SN, Hephzibah Kirubamani N (2012) Insulin response of diabetic pregnant women: analysis of saliva by FTIR study. Indian J Sci Technol 5(3):2318-2324

Stone N, Kendall C, Smith J, Crow P, Barr H (2004) Raman spectroscopy for identification of epithelial cancers. Faraday Discuss 126:141-157

Uceda Otero EP, John P et al (2013) Engineering challenges for instrumenting and controlling integrated organ-on-chip systems. IEEE Trans Biomed Eng 60(3):682-690

Uthayakumar GS, Sivasubramanian A (2013) Biomedical optical analytical techniques to analyze the medicinal drugs and optical properties of tissues. Int J Biomed Eng Technol 12(1):38-59

Uthayakumar GS, Sivasubramanian A (2014) Biomedical optical analytical techniques to analyze the medicinal drugs and optical properties of tissues. Arabian J Sci Eng 39(8):5861-5872

Yin H, Wang Ma S, Chen S (2003) Electrochemical synthesis of silver nanoparticles under protection of poly(Nvinylpyrrolidone). J Phys Chem B 107:8898-8904

Zhang L, Shen YH, Xie AJ, Li SK, Jin BK, Zhang QF (2006) Onestep synthesis of monodisperse silver nanoparticles beneath vitamin E langmuir monolayers. J Phys Chem B 110:6615-6620 